\title{
Permanent Stent Deployment for Preventing Vessel Reocclusion after Mechanical Thrombectomy in Acute Ischemic Stroke
}

\author{
Cheol Su Jwa ${ }^{1}$, Jae Hoon $\mathrm{Kim}^{2}$, Hee In Kang${ }^{2}$, In Seok Bae², Deok Ryeong Kim², Byung Gwan Moon ${ }^{2}$ \\ ${ }^{1}$ Department of Neurosurgery, National Medical Center, Seoul, \\ ${ }^{2}$ Department of Neurosurgery, Nowon Eulji Medical Center, Eulji University College of Medicine, Seoul, Republic of Korea
}

Corresponding author:

Jae Hoon Kim

Department of Neurosurgery, Nowon Eulji Medical Center, Eulji University College of Medicine, 68 Hangeulbiseok-ro, Nowon-gu, Seoul 01830, Republic of Korea Tel: +82-2-970-8268

Fax: $+82-2-979-8268$

E-mail: grimi2@eulji.ac.kr

Received: April 3, 2020

Revised: April 13, 2020

Accepted: April 20, 2020
Objective: To evaluate the efficacy of permanent stent deployment (SD) using a Solitaire retrieval stent for flow restoration in the reoccluded vessel after mechanical thrombectomy (MT). Methods: We retrospectively investigated 35 acute ischemic stroke patients treated by intraarterial MT using a Solitaire retrieval stent between September 2013 and August 2016. We compared the recanalization rate and clinical outcome between the simple thrombectomy (ST) group and the permanent SD group. The degree of vessel recanalization was graded using the thrombolysis in cerebral infarction (TCI) grading system. The clinical outcomes were assessed using National Institute of Health Stroke Scale score and modified Rankin Scale (mRS) score at 3 months. Results: Ten of the 35 subjects were treated with permanent SD. The mean initial National Institute of Health Stroke Scale (NIHSS) score was 16.6 \pm 4.7 in the ST group and 13.0 \pm 4.9 in the SD group. The overall successful recanalization rate (TICI grade 2 or 3 ) was $84 \%$ in the ST group and $70 \%$ in the SD group $(p=0.381)$. Procedure-related complications (symptomatic hemorrhage in 1 case, contrast media leakage in 2 cases) occurred in 3 ST patients during MT. There were no significant differences in favorable outcome (decrement of NIHSS score $\geq 4$ after MT and mRS score $0-3$ at 3 months) between the ST and SD groups ( $p=0.377$ and 0.258 , respectively). Conclusion: Permanent SD as a rescue therapy shows high potential for flow restoration in the reoccluded vessel, especially when simple MT has failed.

Key Words: Ischemia; Stents; Stroke; Thrombectomy

\section{INTRODUCTION}

Restoration of cerebral blood flow within a short time is the key goal of acute ischemic stroke (AIS) therapy. Although Intravenous or intra-arterial thrombolytic has been shown to be effective for treatment of AIS, due to narrow therapeutic time window, contraindications, risk of symptomatic intracerebral hemorrhage (ICH) and low recanalization rates, endovascular treatment including mechanical thrombectomy (MT) has been widely used as an effective treatment tool for recanalization as it can rapidly improve flow of occluded blood vessels, and promotes recovery of neurological function ${ }^{2,8,24)}$.

Several instruments have been used and developed for MT. In particular, MT using a self-expanding retrieval stent resulted in a higher recanalization rate ${ }^{7,23,25,27)}$. Nonetheless, MT using a retrieval stent fails to achieve recanalization in some cases. Recently, permanent stent deployment (SD) as a rescue therapy showed good recanalization rate and favorable outcomes in AIS $^{1,3,4,13,14,16,18-20,26,28,29)}$. Therefore, in the present study we exa- mined the efficacy of permanent SD to prevent reocclusion after MT with a retrieval stent, and to maintain recanalization state.

\section{MATERIALS AND METHODS}

From September 2013 to August 2016, 35 consecutive patients who underwent MT using a 4 or $6 \mathrm{~mm}$ Solitaire (Medtronic, Irvine, CA, USA) retrieval stent for AIS were included. The enrolled patients were divided into the simple thrombectomy (ST) group or the permanent SD group. We compared demographic data (sex and age), clinical data (hypertension, diabetes mellitus, atrial fibrillation, previous cerebrovascular and cardiovascular disease, initial National Institute of Health Stroke Scale (NIHSS) score, location of thrombus, and the use of intravenous recombinant tissue plasminogen activator and post-thrombectomy results (recanalization, ICH, post-thrombectomy NIHSS score, and modified Rankin Scale [mRS] score at 3 months) between the 2 groups. The degree of vessel recanalization 
was graded using the thrombolysis in cerebral infarction (TICI) grading system. Successful recanalization was defined as TICI grade 2 or 3 . Favorable outcomes were defined as: (1) decrement of NIHSS score $\geq 4$ points; and (2) mRS score 0-3 at 3 months.

All MT interventions were performed under local anesthesia. Usually, a 6F Envoy (Codman, Raynham, MA, USA) guiding catheter was placed in the proximal internal carotid artery. Once the microguidewire crossed the occlusion site, Rebar (Medtronic) microcatheter was advanced over the microwire and navigated distal to the clot. The Solitaire stent was then deployed for 5 to $10 \mathrm{~min}$. Under continuous aspiration through the guiding catheter, the stent was retrieved together with the microcatheter. This procedure was repeated 3 to 5 times to

Table 1. Analysis of baseline characteristics of study population according to the thrombectomy method

\begin{tabular}{|c|c|c|c|}
\hline & $\begin{array}{l}\text { ST group } \\
(\mathrm{n}=25)\end{array}$ & $\begin{array}{c}\text { SD group } \\
(n=10)\end{array}$ & $\mathrm{p}$-value \\
\hline Sex & & & 0.471 \\
\hline Male & 14 & 4 & \\
\hline Female & 11 & 6 & \\
\hline Age (years) & $71.3 \pm 8.1$ & $70.4 \pm 12.6$ & 0.872 \\
\hline Hypertension & & & 0.444 \\
\hline Yes & 17 & 5 & \\
\hline No & 8 & 5 & \\
\hline Diabetes mellitus & & & 1.000 \\
\hline Yes & 8 & 3 & \\
\hline No & 17 & 7 & \\
\hline Atrial fibrillation & & & 0.151 \\
\hline Yes & 17 & 4 & \\
\hline No & 8 & 6 & \\
\hline Cardiovascular disease & & & 0.303 \\
\hline Yes & 4 & 0 & \\
\hline No & 21 & 10 & \\
\hline Cerebrovascular disease & & & 1.000 \\
\hline Yes & 6 & 2 & \\
\hline No & 19 & 8 & \\
\hline Initial NIHSS score & $16.6 \pm 4.7$ & $13.0 \pm 4.9$ & 0.059 \\
\hline Location of thrombus & & & 0.387 \\
\hline M1 & 14 & 7 & \\
\hline M2 & 1 & 1 & \\
\hline ICA & 10 & 2 & \\
\hline IV rtPA & & & 0.444 \\
\hline Yes & 8 & 5 & \\
\hline No & 17 & 5 & \\
\hline
\end{tabular}

The data is presented as number or mean \pm standard deviation. ST: simple thrombectomy; SD: stent deployment; NIIHSS: National Institute of Health Stroke Scale; M: middle cerebral artery; ICA: internal carotid artery; IV rtPA: intravenous recombinant tissue plasminogen activator. achieve recanalization. When complete reocclusion, distal flow delay, and focal stenotic lesion were found after stent removal, we performed permanent SD. A glycoprotein IIb/IIIa inhibitor (Aggrastat; Merck \& Co, Inc., Kenilworth, NJ, USA) was administered intravenously as a loading dose $(0.4 \mathrm{mcg} / \mathrm{kg})$ for $30 \mathrm{~min}$, followed by continuous infusion for $24 \mathrm{hr}(0.1 \mathrm{mcg} / \mathrm{kg} / \mathrm{min})$. Thereafter, dual anti-platelets (acetyl- salicylic acid $100 \mathrm{mg}$ and clopidogrel $75 \mathrm{mg}$ ) were given orally.

All continuous variables are presented as the mean \pm standard deviation. We used the Mann-Whitney U test for continuous variables and the Fisher's exact test for categorical variables. A 2-tailed value of $\mathrm{p} \leq 0.05$ was considered statistically significant. All statistical analyses were performed using statistical software (SPSS 20.0 for Windows; SPSS Inc., Chicago, IL, USA).

\section{RESULTS}

The demographic and clinical characteristics of the patients are summarized in Table 1 . Successful recanalization was achieved in 28 patients (80\%) after MT. Ten of the 35 patients were treated with permanent SD. The mean initial NIHSS score was 16.6 \pm 4.7 in the ST group and 13.0 \pm 4.9 in the SD group. The overall successful recanalization rate (TICI grade 2 or 3 ) was $84 \%$ in the ST group and $70 \%$ in the SD group ( $\mathrm{p}=0.381$ ). Procedure-related complications (symptomatic ICH in 1 case, contrast media leakage in 2 cases) occurred in 3 ST patients during MT. The changes in NIHSS score after MT in each patient

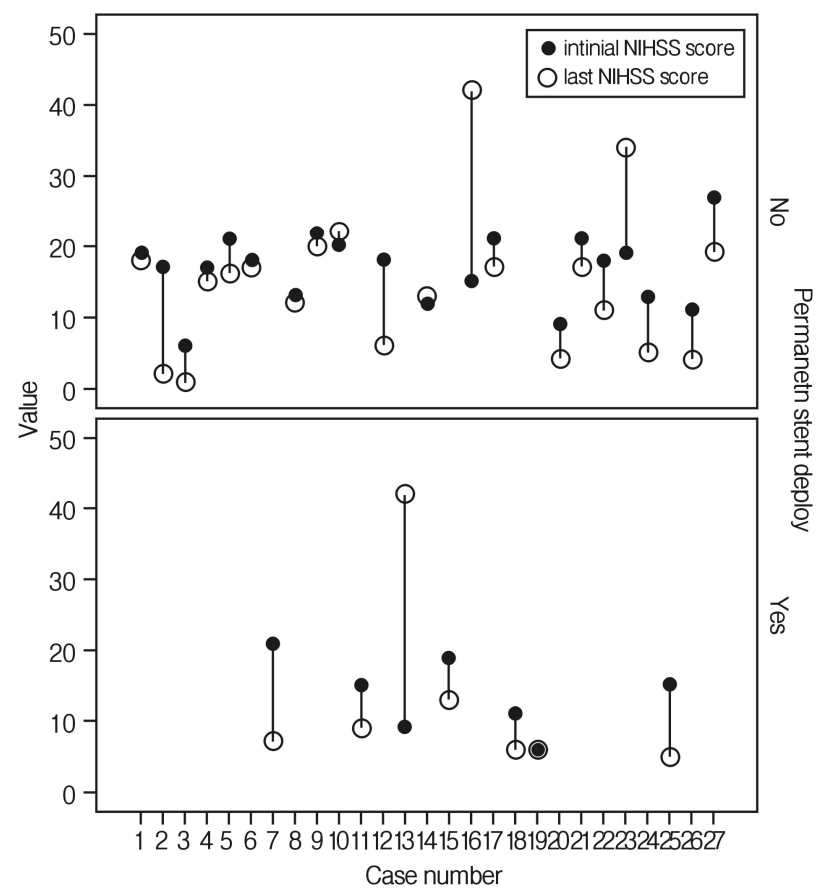

Fig. 1. Dropline graph showing the changes of National Institute of Health Stroke Scale score in each patient before and after mechanical thrombectomy.

8 www.thenerve.net 
are shown in Fig. 1. There were no significant differences in favorable outcomes (decrement of NIHSS score $\geq 4$ after MT and $\mathrm{mRS}$ score $0-3$ at 3 months) between the ST and SD groups $(\mathrm{p}=0.377$ and 0.258 , respectively) (Table 2$)$. In subgroup analysis, the reasons for permanent SD in 10 patients were complete reocclusion $(n=4)$, focal stenosis $(n=4)$, proximal vessel tortuosity with imminent therapeutic window $(n=1)$, and distal flow delay with focal stenosis $(n=1)$ (Table 3$)$.

\section{DISCUSSION}

The use of MT with a retrieval stent was recently reported to have excellent efficacy ${ }^{2,5-7,12,15,21-23,25,27)}$. Furthermore, the safety problems related to the procedure were lower or similar to those of other methods ${ }^{2,5,7,15,22,23,27)}$.

However, MT using a retrieval stent may fail in some patients, resulting in a significant increase in mortality ${ }^{11)}$. Because recanalization of the occluded vessel in AIS treatment is closely

Table 2. Analysis of clinical outcomes according to the thrombectomy method

\begin{tabular}{|c|c|c|c|}
\hline & $\begin{array}{l}\text { ST group } \\
(\mathrm{n}=25)\end{array}$ & $\begin{array}{l}\text { SD group } \\
(n=10)\end{array}$ & $\mathrm{p}$-value \\
\hline Recanalization & & & 0.381 \\
\hline Yes (TICl 2, 3) & 21 & 7 & \\
\hline $\mathrm{No}(\mathrm{TICl} 0,1)$ & 4 & 3 & \\
\hline Post-MT NIHSS score & $15.3 \pm 10.9$ & $10.9 \pm 11.2$ & 0.131 \\
\hline$\Delta \mathrm{NIHSS}$ score ${ }^{*}$ & $-1.3 \pm 10.2$ & $-2.1 \pm 12.9$ & 0.377 \\
\hline Post-MT hemorrhage & & & 0.542 \\
\hline Yes & 3 & 0 & \\
\hline No & 22 & 10 & \\
\hline Immediate outcome & & & 0.709 \\
\hline Favorable $^{+}$ & 15 & 7 & \\
\hline Unfavorable $^{\neq}$ & 10 & 3 & \\
\hline $\mathrm{mRS}$ score at 3 months & & & 0.258 \\
\hline $0-3$ & 7 & 5 & \\
\hline $4-6$ & 18 & 5 & \\
\hline
\end{tabular}

The data is presented as number or mean \pm standard deviation. ST: simple thrombectomy; SD: stent deployment; $\mathrm{TICl}$ : thrombolysis in cerebral infarction; MT: mechanical thrombectomy; NIHSS: National Institutes of Health Stroke Scale; mRS: modified Rankin Scale.

$* \Delta \mathrm{NIHSS}$ score $=$ Initial NIHSS score - Post-MT NIHSS score. ${ }^{+}$Favorable: NIHSS score improvement $\geq 4$. ${ }^{+}$Unfavorable: NIHSS score improvement $<4$. related to good prognosis, recanalization of the occluded vessels is the most important factors for effective treatment ${ }^{8,24)}$.

Repeated MT using a retrieval stent can result in vessel injury, such as perforation or dissection, leading to a symptomatic ICH. Delayed stenosis or reocclusion may also occur due to vascular intimal injury ${ }^{910)}$. Furthermore, the migration of thromboembolic fragments may be problematic during retrieval using a stent, while some emboli may not be affected by the thrombolytic agent due to mature and fibrinous consistency, and MT may be difficult if the emboli are firmly attached to the vessel intima. In addition, in cases where a stenotic lesion contains an atherosclerotic plaque, recanalization using simple MT is often difficult.

Thus, permanent stent placement is considered as a rescue therapy when recanalization fails or MT is difficult. Indeed, recent studies have shown that permanent stent placement is effective method in treating AIS ${ }^{1,3,4,13,14,16,18-20,26,28,29)}$.

Permanent stent placement as a rescue therapy has several potential advantages. First, there is no need for multiple repetitive procedures, which allows rapid recanalization and is less likely to damage blood vessels. Second, recanalization can be achieved by compressing and fixing the thrombus to the vessel wall, even if a mature and fibrinous clot exists or a thrombus is strongly attached to the vessel wall. Third, even if there is a stenotic lesion containing an atherosclerotic plaque, recanalization with permanent stent placement is advantageous as it may slightly widen the vessel. Nevertheless, although there was no evidence of in-stent stenosis in patients at 6-month follow-up after permanent stent placement, there are some concerns such as late reocclusion and in-stent stenosis associated with permanent stent placement ${ }^{9,17)}$. Several studies have also reported increased tendency for bleeding because of dual antiplatelet medication after permanent stent placement ${ }^{16,19,20)}$. In this study, symptomatic ICH did not occur in SD group, but there was no statistical significance.

In our study, 35 patients with AIS were enrolled and 10 patients underwent permanent stent placement. It is reasonable to compare the usefulness of permanent SD as a rescue therapy in failed MT group. However, due to small sample size and the changes of MT protocol during study period, we did not directly compare ST group with SD group following failed MT. In subgroup analysis, permanent stent placement was effective, when focal stenosis or complete reocclusion was evident but the thrombus did not come out. In addition, higher rate of permanent SD compared with other studies may be attributed to

Table 3. Analysis of the reasons for permanent stent deployment in 10 patients

\begin{tabular}{llc}
\hline \hline Reasons & $\mathrm{n}$ & Successful recanalization \\
\hline Complete reocclusion & 4 & 4 \\
Focal stenosis & 4 & 3 \\
Tortuous proximal vessel with imminent therapeutic window & 1 & 0 \\
Distal flow delay with focal stenosis & 1 & 0 \\
\hline
\end{tabular}


the small sample size. Nevertheless, we found no differences in favorable outcome between the 2 groups, suggesting that the efficacy of permanent stent placement as a rescue therapy after failure of MT may equivalent to patients receiving simple MT.

Our study has several limitations. First, this study was limited by its retrospective nature and small sample size. Second, we did not perform permanent SD in the earlier period of study. During study period, MT protocol was changed to perform permanent SD based on consensus among attending physicians (neurologists and interventionists). Therefore, direct comparison of the degree of recanalization rate and clinical outcomes in this heterogenous group may cofound our results. In addition, late reocclusion and in-stent thrombosis caused by permanent stent placement were not evaluated as the follow-up period was short.

\section{CONCLUSION}

Permanent SD showed high potential for flow restoration in the reoccluded vessel, especially when simple MT had failed. A long-term follow-up is required to verify the incidence of late complications.

Previous presentation: Oral presentation at Annual Meeting of Society of Korean Endovascular Neurosurgeons, 2016

\section{CONFLICTS OF INTEREST}

No potential conflict of interest relevant to this article was reported.

\section{REFERENCES}

1. Baek JH, Kim BM, Kim DJ, Heo JH, Nam HS, Yoo J: Stenting as a rescue treatment after failure of mechanical thrombectomy for anterior circulation large artery occlusion. Stroke 47:23602363, 2016

2. Berkhemer OA, Fransen PS, Beumer D, van den Berg LA, Lingsma $\mathrm{HF}$, Yoo AJ, et al.: A randomized trial of intraarterial treatment for acute ischemic stroke. N Engl J Med 372:11-20, 2015

3. Brekenfeld C, Schroth G, Mattle HP, Do DD, Remonda L, Mordasini $P$, et al.: Stent placement in acute cerebral artery occlusion: use of a self-expandable intracranial stent for acute stroke treatment. Stroke 40:847-852, 2009

4. Brekenfeld C, Tinguely P, Schroth G, Arnold M, El-Koussy M, Nedeltchev K, et al.: Percutaneous transluminal angioplasty and stent placement in acute vessel occlusion: evaluation of new methods for interventional stroke treatment. AJNR Am J Neuroradiol 30:1165-1172, 2009

5. Castaño C, Dorado L, Guerrero C, Millan M, Gomis M, Perez de la Ossa N, et al.: Mechanical thrombectomy with the Solitaire $\mathrm{AB}$ device in large artery occlusions of the anterior circulation: a pilot study. Stroke 41:1836-1840, 2010
6. Cohen JE, Gomori JM, Leker RR, Moscovici S, RamirezDenoriega F, Itshayek E: Recanalization with stent-based mechanical thrombectomy in anterior circulation major ischemic stroke. J Clin Neurosci 19:39-43, 2012

7. Cohen JE, Rabinstein AA, Ramirez-de-Noriega F, Gomori JM, Itshayek E, Eichel R, et al.: Excellent rates of recanalization and good functional outcome after stent-based thrombectomy for acute middle cerebral artery occlusion. Is it time for a paradigm shift? J Clin Neurosci 20:1219-1223, 2013

8. Day JS, Hurley MC, Chmayssani M, Rahme RJ, Alberts MJ, Bernstein RA, et al.: Endovascular stroke therapy: a single-center retrospective review. Neurosurg Focus 30:E10, 2011

9. Enomoto Y, Takagi T, Matsubara H, Tsujimoto M, Yamauchi $\mathrm{K}$, Yoshimura S, et al.: Delayed stenosis in the intracranial vessels following endovascular treatment for acute stroke. J Vasc Interv Radiol 26:1814-1819, 2015

10. Enomoto Y, Yoshimura S, Egashira Y, Takagi T, Tsujimoto M, Iwama T: Long-term magnetic resonance angiography follow-up for recanalized vessels after mechanical thrombectomy. J Stroke Cerebrovasc Dis 23:2834-2839, 2014

11. Gascou G, Lobotesis K, Machi P, Maldonado I, Vendrell JF, Riquelme C, et al.: Stent retrievers in acute ischemic stroke: complications and failures during the perioperative period. AJNR Am J Neuroradiol 35:734-740, 2014

12. Gralla J, Brekenfeld C, Mordasini P, Schroth G: Mechanical thrombolysis and stenting in acute ischemic stroke. Stroke 43: 280-285, 2012

13. Guo XB, Song LJ, Guan S: Emergent angioplasty and stent placement recanalization without thrombolysis in acute middle cerebral artery occlusions. J Stroke Cerebrovasc Dis 22:694-699, 2013

14. Gupta R, Tayal AH, Levy EI, Cheng-Ching E, Rai A, Liebeskind DS, et al.: Intra-arterial thrombolysis or stent placement during endovascular treatment for acute ischemic stroke leads to the highest recanalization rate: results of a multicenter retrospective study. Neurosurgery 68:1618-1622, 2011

15. Koh JS, Lee SJ, Ryu CW, Kim HS: Safety and efficacy of mechanical thrombectomy with solitaire stent retrieval for acute ischemic stroke: a systematic review. Neurointervention 7:1-9, 2012

16. Levy EI, Mehta R, Gupta R, Hanel RA, Chamczuk AJ, Fiorella $\mathrm{D}$, et al.: Self-expanding stents for recanalization of acute cerebrovascular occlusions. AJNR Am J Neuroradiol 28:816-822, 2007

17. Levy EI, Rahman M, Khalessi AA, Beyer PT, Natarajan SK, Hartney ML, et al.: Midterm clinical and angiographic followup for the first food and drug administration-approved prospective, single-arm trial of primary stenting for stroke: SARIS (StentAssisted Recanalization for acute Ischemic Stroke). Neurosurgery 69:915-920, 2011

18. Levy EI, Siddiqui AH, Crumlish A, Snyder KV, Hauck EF, Fiorella DJ, et al.: First Food and Drug Administration-approved prospective trial of primary intracranial stenting for acute stroke: SARIS (stent-assisted recanalization in acute ischemic stroke). Stroke 40:3552-3556, 2009

19. Linfante I, Samaniego EA, Geisbusch P, Dabus G: Self-expandable stents in the treatment of acute ischemic stroke refractory to current thrombectomy devices. Stroke 42:2636-2638, 2011 20. Mocco J, Hanel RA, Sharma J, Hauck EF, Snyder KV, Natarajan 
SK, et al.: Use of a vascular reconstruction device to salvage acute ischemic occlusions refractory to traditional endovascular recanalization methods. J Neurosurg 112:557-562, 2010

21. Papanagiotou P, Roth C, Walter S, Behnke S, Politi M, Fassbender $\mathrm{K}$, et al.: Treatment of acute cerebral artery occlusion with a fully recoverable intracranial stent: a new technique. Circulation 121:2605-2606, 2010

22. Park H, Hwang GJ, Jin SC, Jung CK, Bang JS, Han MK, et al.: A retrieval thrombectomy technique with the Solitaire stent in a large cerebral artery occlusion. Acta Neurochir (Wien) 153: 1625-1631, 2011

23. Park JH, Park SK, Jang KS, Jang DK, Han YM: Critical use of balloon angioplasty after recanalization failure with retrievable stent in acute cerebral artery occlusion. J Korean Neurosurg Soc 53:77-82, 2013

24. Rha JH, Saver JL: The impact of recanalization on ischemic stroke outcome: a meta-analysis. Stroke 38:967-973, 2007

25. Roth C, Papanagiotou P, Behnke S, Walter S, Haass A, Becker
C, et al.: Stent-assisted mechanical recanalization for treatment of acute intracerebral artery occlusions. Stroke 41:2559-2567, 2010

26. Sauvageau E, Samuelson RM, Levy EI, Jeziorski AM, Mehta RA, Hopkins LN: Middle cerebral artery stenting for acute ischemic stroke after unsuccessful Merci retrieval. Neurosurgery 60:701-706, 2007

27. Stampfl S, Hartmann M, Ringleb PA, Haehnel S, Bendszus M, Rohde S: Stent placement for flow restoration in acute ischemic stroke: a single-center experience with the Solitaire stent system. AJNR Am J Neuroradiol 32:1245-1248, 2011

28. Xavier AR, Tiwari A, Kansara A: Angioplasty and stenting for mechanical thrombectomy in acute ischemic stroke. Neurology 79:S142-S147, 2012

29. Zaidat OO, Wolfe T, Hussain SI, Lynch JR, Gupta R, Delap $\mathrm{J}$, et al.: Interventional acute ischemic stroke therapy with intracranial self-expanding stent. Stroke 39:2392-2395, 2008 